\title{
ANALISA BRAND EQUITY TERHADAP BRAND LOYALITAS PT. TRANSJAKARTA
}

\author{
Wendy Fernando \\ Program Studi Magister Manajemen Universitas Tarumanagara \\ wendy.fernando_93@yahoo.com
}

\begin{abstract}
This study aims to determine whether there is influence of Brand Awareness to Brand Reputation, to know whether there is influence of Service Quality to Brand Reputation, to know whether influence of Staff Behavior to Brand Reputation, to know whether there is influence of Self Congruence to Brand Reputation, and to know whether there is influence of Brand Identification to Brand Reputation, to know whether there is influence of Brand Association to Brand Reputation, to know whether there is influence of Brand Reputation to Brand Satisfaction, to know whether there is influence of Brand Satisfaction to Brand Trust, to know whether there is influence of Brand Trust to Brand Loyalty, The sample used is 600 respondents who become consumer companies with data analysis techniques that are multiple regression using AMOS program.
\end{abstract}

Keywords : Brand Equity, Brand Loyalty, Brand Awareness, Brand Reputation, Brand Trust, Brand Satisfaction, Staff Behavior, Service Quality.

\section{PENDAHULUAN}

Dalam dunia pemasaran dewasa ini, persaingan yang terjadi bukan lagi hanya sekedar pertempuran produk, melainkan merupakan pertempuran persepsi konsumen, dimana persepsi konsumen dapat dibangun melalui jalur merek. Membangun merek yang kuat merupakan suatu hal yang penting bagi perusahaan. Berdasarkan data BPS (2015) mobilitas penduduk yang tinggi di Jakarta mengharuskan penerapan sistem transit cepat berskala massal atau Mass Rapid Transit. Berdasarkan hasil survei yang dilakukan oleh YLKI (2010) pada bulan Maret 2010 terhadap 3.000 responden pengguna Transjakarta di seluruh koridor dengan kompoosisi 40 persen pria dan 60 persen wanita mengungkapkan bahwa keluhan utama para pengguna Bus Transjakarta hampir seluruhnya berkutat pada masalah waktu tunggu bus yang lebih dari 5 menit. Dalam hasil survei yang dilakukan oleh YLKI (2010) pada pertengahan tahun 2010, sebanyak 41,4 persen responden mengeluhkan waktu tunggu dihalte sebagai pengalaman negatif saat menggunakan Bus Transjakarta. Sebanyak 26.92 responden mengeluhkan angkutan massal ini sering over kapasitas. Mereka juga menganggap kondisi ini membuat kejahatan di Bus Transjakarta meningkat (Priliawito \& AlYamani, 2010). Suatu produk dikatakan memiliki merek yang kuat dipasaran apabila produk tersebut memiliki brand equity yang kuat (Durianto, 2004). Dengan brand equity yang kuat, perusahaan memiliki suatu keunggulan bersaing yang sulit untuk ditiru oleh para pesaingnya.

\section{Landasan Teori}

Merek mengidentifikasi pembuat produk dan memungkinkan konsumen untuk menetapkan tanggung jawab untuk kinerja untuk pembuat atau distributor. Merek melakukan sejumlah fungsi bagi konsumen dan perusahaan (Kotler dan Keller, 2016). Di dalam pemasaran suatu usaha, unsur brand atau merek memiliki peran penting. (Kotler 
dan Keller, 2012). Menurut Kotler (2012), merek merupakan janji penjual untuk secara konsisten memberikan fitur, manfaat, dan jasa tertentu kepada pembeli. Merek dapat memiliki enam tingkatan yaitu: Atribut, Manfaat, Nilai, Budaya, Kepribadian, Pemakai. Nam et al., (2011) memperkenalkan model ekuitas merek alternative dengan mencakup 7 dimensi dan rangkaian yang berbeda yaitu : Physical Quality, Staff Behavior, Ideal SelfCongruence, Brand Identification, Lifestyle Congruence, Brand Satisfaction, dan Brand Loyalty. brand awareness telah terbukti mempengaruhi persepsi, keinginan, dan bahkan perilaku seseorang. Kesadaran suatu merek bisa menjadi sinyal keberhasilan yang bisa menjadi bahan penting bagi sektor industri (Aaker, 2014). Brand association termasuk dalam produk atribut (Crest, Volvo), Desain (Calvin Klein, Apple), Program Sosial (Avon, Patagonia), Kualitas (Lexus, Southwest Airlines) Inovasi (3M, Virgin), System Solutions (IBM, Salesforce.com), User imagery (Mercedes, Nike)semua yang berhubungan dengan pelanggan terhadap merek. Mereka bisa menjadi dasar dari customer relationship, purchase decision, user experience, dan brand loyalty (Aaker, 2014). Brand Loyalty merupakan inti dari segala brand value, karena begitu diperoleh, maka loyalitas akan terus berlanjut. Memecahkan konsumen kompetitor loyal sulit dan mahal (Aaker, 2014). 2 studi mendukung bahwa efek dari Brand Loyalty di industri retail. Nam et al., (2011).

Consumer-Based Brand Equity: Three Competing Models

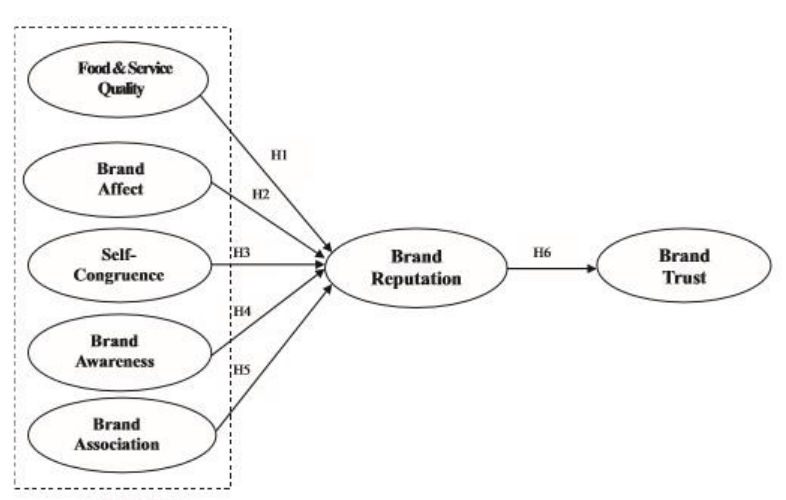

Model 1: Cifci et al., (2016)

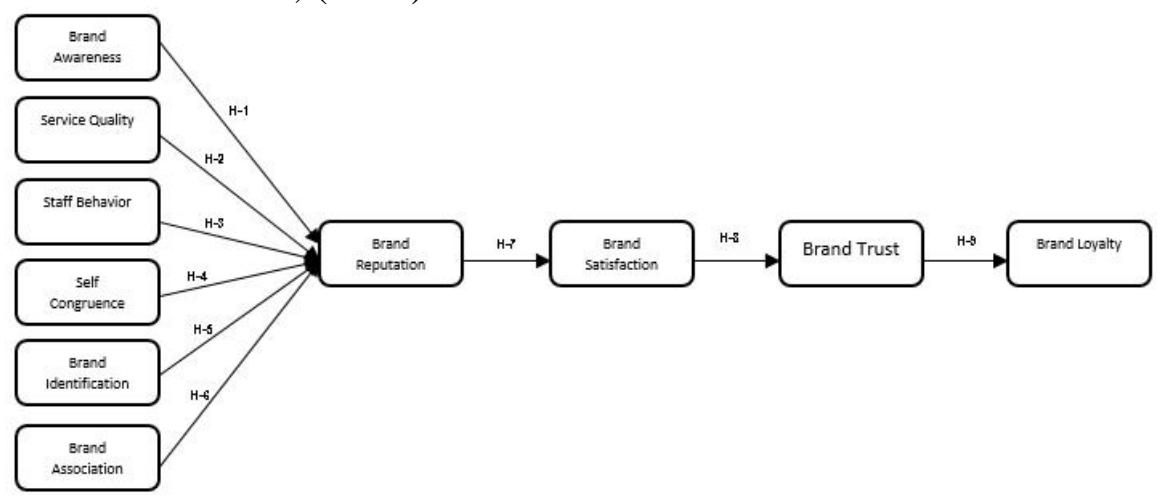

Model 3: Extended model of Cifci et al.

Model 3 adalah penggabungan dari model Cifci et al. Dan Jin dan Leslie.

\section{Rancangan Penelitian}

3.1 Rancangan Penelitian

Menurut Sekaran dan Bougie (2013), menyatakan bahwa penelitian pada dasarnya dapat berupa eksploratif dan deskriptif. Dimana penelitian eksploratif merupakan penelitian yang bertujuan untuk menggali secara luas tentang sebab-sebab atau hal-hal yang mempengaruhi terjadinya ssesuatu, mengumpulkan data yang mendeskripsikan karakteristik dari person, peristiwa, atau situasi. Penelitian deskriptif 
pada dasarnya adalah kuantitatif maupun kualitatif dan mungkin melibatkan pengumpulan data kuantitatif seperti penilaian kepuasan, angka produksi, angka penjualan, atau data demografi, tetapi juga mungkin memerlukan pengumpulan informasi kualitatif.

\subsection{Metode}

Dalam pengukuran variabel ini, peneliti akan menggunakan skala Likert untuk mengukur variabel Brand Awareness, Physical Quality, Staff Behavior, Self Congruence, Brand Identification, Brand Association, Brand Reputation, Brand Satisfaction, Brand Trust, Brand Loyalty. Skala likert yang digunakan untuk mengukur dengan 1 adalah "Sangat Tidak Setuju" dan 7 adalah "Sangat Setuju" . Teknik pengambilan sampel yang digunakan adalah dengan teknik non-probability sampling yang menggunakan pendekatan purposive sampling. Menurut Malholtra (2010), purposive sampling merupakan teknik penentuan sampel berdasarkan pertimbangan tertentu yang dianggap cocok dengan karakteristik sampel yang ditentukan akan dijadikan sampel. Besaran sampel penelitian yang menggunakan metode SEM ditentukan berdasarkan jumlah indikator dikalikan lima (Malholtra, 2010). Indikator variabel pada kuisioner penelitian ini berjumlah 57 indikator, sehingga minimal sampel yang harus dikumpulkan oleh peneliti berjumlah 285 responden. Dalam penelitian ini target responden yang akan digunakan sebanyak 600 responden. Setelah itu, akan dilakukan uji validitas dan reliabilitas atas hasil kuesioner yang telah diperoleh. Pengambilan sampel dilakukan dengan cara menyebarkan kuesioner. Jangka waktu penyebaran kuesioner pada penelitian ini adalah seminggu, yaitu hari senin hingga minggu pada tanggal 1 hingga 20 november 2017. Jumlah pengambilan sampel yang diperoleh sebanyak 600 responden dengan menggunakan system penyebaran manual. Lokasi pengambilan sampel dilakukan di halte busway dan masyarakat umum.

\section{Analisa dan Pembahasan}

\subsection{Analisis Pendahuluan}

Untuk mengetahui apakah para responden telah memahami isi kuesioner dengan jelas, maka dilakukan analisis pendahuluan melalui wording test. Peneliti menyebarkan isi kuesioner kepada 5 responden yang pernah menggunakan Transjakarta agar dapat lebih memahami setiap pertanyaan yang diberikan. Tujuan dari wording test ini. Setelah wording test, tahap selanjutnya yaitu pre-test kuesioner, maholtra (2010) mengatakan bahwa pre-test merupakan tes kuesioner pada sebuah sampel kecil, yang biasanya dilakukan kepada 51 responden pengguna Transjakarta yang nantinya akan digunakan untuk mengidentifikasi serta mengeliminasi masalahmasalah potensial. Dari hasil pre-test yang didapatkan kemudian dilakkan Analisis Validitas dan Analisis Reliabilitas. Analisa Validitas dilakukan dengan Confirmatory Factor Analysis (CFA) untuk mengetahui ketepatan instrumen dalam mengukur variabel yang akan diteliti. Confirmatory Factor Analysis (CFA) 


\subsection{Measurement Model (Goodness of Fit Measurement Model)}

Uji Goodness of Fit Measurement Model

\begin{tabular}{|l|l|l|l|}
\hline $\begin{array}{l}\text { Ukuran } \\
\text { GoF }\end{array}$ & $\begin{array}{l}\text { Target } \\
\text { Kecocokan }\end{array}$ & $\begin{array}{l}\text { Hasil Output } \\
\text { Model }\end{array}$ & Keterangan \\
\hline GFI & \multicolumn{1}{|c|}{$>0,9$} & 0,80 & Poor fit \\
\hline AGFI & $>0,9$ & 0,78 & Poor Fit \\
\hline CMIN/DF & $<3$ & 2.61 & Good Fit \\
\hline RMR & $<0,08$ & 0,04 & Good Fit \\
\hline RMSEA & $<0,08$ & 0,05 & Good Fit \\
\hline NFI & $\geq 0,90$ & 0,76 & Poor Fit \\
\hline CFI & $>0,9$ & 0,83 & Poor Fit \\
\hline TLI & $\geq 0,90$ & 0,82 & Poor Fit \\
\hline
\end{tabular}

Indikator yang dihapus oleh peneliti adalah sebagai berikut: X1.5, X1.6, X2.1, X2.2, X2.4, X3.1, X4.3, X4.5, X5.1, X5.2, X6.4, X6.5, X6.6, X6.7, X7.4, X7.5, X7.6, X8.1, X8.2, X9.1, X9.5, X2.3, X4.4, X6.3, X10.1, X10.2, dan X10.3 Sehingga model pengukuran pada gambar output menunjukan nilai Goodness of Fit yang baik.

\begin{tabular}{|l|l|l|l|}
\hline Ukuran GoF & Target Kecocokan & Hasil Output Model & Keterangan \\
\hline GFI & \multicolumn{1}{|c|}{$>0,9$} & 0,93 & Good Fit \\
\hline AGFI & $>0,9$ & 0,91 & Good Fit \\
\hline CMIN/DF & $<3$ & 1.93 & Good Fit \\
\hline RMR & $<0,08$ & 0,03 & Good Fit \\
\hline RMSEA & $<0,08$ & 0,04 & Good Fit \\
\hline NFI & $\geq 0,90$ & & Good Fit \\
\hline CFI & $>0,9$ & 0,96 & Good Fit \\
\hline TLI & $\geq 0,90$ & 0,95 & Good Fit \\
\hline
\end{tabular}

Uji Goodness of Fit Measurement Model 


\section{Scales and Factor Loadings}

\begin{tabular}{|c|c|c|}
\hline Scales & Measurement & Factor Loading \\
\hline \multirow{4}{*}{ Brand Awareness } & Saya dapat mengenali merek ini di kategori yang sama. & 0.746 \\
\hline & Saya sadar dengan merek ini. & 0.841 \\
\hline & $\begin{array}{l}\text { Beberapa karakteristik dari merek ini terlintas cepat di pikiran } \\
\text { saya. }\end{array}$ & 0.775 \\
\hline & Mudah bagi saya untuk mengidentifikasi merek ini. & 0.741 \\
\hline \multirow[t]{2}{*}{$\begin{array}{l}\text { Service Quality: } \\
\text { Physical Quality }\end{array}$} & $\begin{array}{l}\text { Material dan fasilitas yang terkait (Bus, Halte, Fasilitas } \\
\text { disabilitas, Toilet) menarik secara visual. }\end{array}$ & 0.672 \\
\hline & Tata letak halte merek ini rapih. & 0.800 \\
\hline \multirow{4}{*}{$\begin{array}{l}\text { Service Quality: } \\
\text { Staff Behavior }\end{array}$} & Karyawan dari merek ini sangat bermanfaat. & 0.739 \\
\hline & Karyawan dari merek ini sangat ramah. & 0.844 \\
\hline & Karyawan dari merek ini bertalenta & 0.837 \\
\hline & Karyawan dari merek ini memperlihatkan keahlian alami. & 0.735 \\
\hline \multirow[b]{2}{*}{ Self Congruence } & Pelanggan dari merek ini berkepribadian sama seperti saya & 0.716 \\
\hline & $\begin{array}{l}\text { Pelanggan dari merek ini merefleksikan diri mereka seperti } \\
\text { yang saya kira }\end{array}$ & 0.773 \\
\hline \multirow{3}{*}{$\begin{array}{l}\text { Brand } \\
\text { Identification }\end{array}$} & Saya memiliki perasaan yang sangat kuat atas merek ini. & 0.677 \\
\hline & Merek ini telah menjadi bagian dari diri saya & 0.890 \\
\hline & Merek ini memiliki arti tersendiri bagi saya & 0.808 \\
\hline \multirow{2}{*}{$\begin{array}{l}\text { Brand } \\
\text { Association }\end{array}$} & Menurut saya merek ini memiliki logo yang atraktif. & 0.735 \\
\hline & Saya menyukai logo dari merek ini & 0.768 \\
\hline \multirow{3}{*}{ Brand Reputation } & Menurut saya merek ini bereputasi & 0.744 \\
\hline & Menurut saya merek ini cukup memberikan klaim yang jujur & 0.755 \\
\hline & $\begin{array}{l}\text { Menurut saya merek ini telah memberikan produk atau jasa } \\
\text { yang bernilai }\end{array}$ & 0.686 \\
\hline \multirow{3}{*}{$\begin{array}{l}\text { Brand } \\
\text { Satisfaction }\end{array}$} & Buruk sekali $\leftarrow--------\rightarrow$ Senang & 0.731 \\
\hline & Sangat tidak puas $\leftarrow---------\rightarrow$ Sangat puas & 0.922 \\
\hline & Luar biasa tidak puas $\leftarrow-----------\rightarrow$ Luar biasa puas & 0.731 \\
\hline \multirow{3}{*}{ Brand Trust } & Merek ini menjamin kepuasan & 0.706 \\
\hline & Saya memiliki kepercayaan diri terhadap merek ini & 0.828 \\
\hline & Saya percaya dengan layanan yang diberikan merek ini & 0.759 \\
\hline \multirow{3}{*}{ Brand Loyaly } & Menggunakan merek ini meskipun harga tiket cukup & 0.649 \\
\hline & Merasa setia akan menggunakan merek ini & 0.857 \\
\hline & Tidak akan menggunakan merek lain & 0.646 \\
\hline
\end{tabular}


(Average Variance Extracted)

\begin{tabular}{|l|l|l|l|}
\hline Laten & $\begin{array}{l}\text { Cronbach's } \\
\text { Alpha } \geq \mathbf{0 . 6}\end{array}$ & AVE $>\mathbf{0 . 5}$ & Keterangan \\
\hline Brand Awareness & 0.855 & 0.6034 & Reliable \& Valid \\
\hline Physical Quality & 0.795 & 0.5458 & Reliable \& Valid \\
\hline Staff Behavior & 0.873 & 0.6248 & Reliable \& Valid \\
\hline Self-Congruence & 0.763 & 0.5560 & Reliable \& Valid \\
\hline Brand Identification & 0.864 & 0.6344 & Reliable \& Valid \\
\hline Brand Association & 0.789 & 0.5650 & Reliable \& Valid \\
\hline Brand Reputation & 0.810 & 0.5314 & Reliable \& Valid \\
\hline Brand Satisfaction & 0.813 & 0.6357 & Reliable \& Valid \\
\hline Brand Trust & 0.832 & 0.5867 & Reliable \& Valid \\
\hline Brand Loyal & 0.796 & 0.5243 & Reliable \& Valid \\
\hline
\end{tabular}

Hasil Discriminant Validity

\subsection{Struktural Model}

Struktural model digunakan untuk menguji hipotesis model penelitian dengan melihat apakah terdapat pengaruh yang signifikan antara masing - masing laten pada model penelitian. Berdasarkan hasil uji Goodness of Fit menunjukan bahwa hasil output

\begin{tabular}{|l|l|l|l|l|l|l|l|l|l|l|}
\hline Construct Scale & $\mathbf{1}$ & $\mathbf{2}$ & $\mathbf{3}$ & $\mathbf{4}$ & $\mathbf{5}$ & $\mathbf{6}$ & $\mathbf{7}$ & $\mathbf{8}$ & $\mathbf{9}$ & $\mathbf{1 0}$ \\
\hline Brand Awareness & $\mathbf{0 . 6 0}$ & & & & & & & & & \\
\hline Physical Quality & 0.10 & $\mathbf{0 . 5 5}$ & & & & & & & & \\
\hline Staff Behavior & 0.15 & 0.43 & $\mathbf{0 . 6 2}$ & & & & & & & \\
\hline Self-Congruence & 0.11 & 0.19 & 0.15 & $\mathbf{0 . 5 6}$ & & & & & & \\
\hline $\begin{array}{l}\text { Brand } \\
\text { Identification }\end{array}$ & 0.02 & 0.01 & 0.01 & 0.05 & $\mathbf{0 . 6 3}$ & & & & & \\
\hline Brand Association & 0.03 & 0.01 & 0.07 & 0.11 & 0.05 & $\mathbf{0 . 5 7}$ & & & & \\
\hline Brand Reputation & 0.19 & 0.19 & 0.16 & 0.10 & 0.02 & 0.12 & $\mathbf{0 . 5 3}$ & & & \\
\hline Brand Satisfaction & 0.10 & 0.14 & 0.14 & 0.07 & 0.01 & 0.06 & 0.14 & $\mathbf{0 . 6 4}$ & & \\
\hline Brand Trust & 0.13 & 0.17 & 0.19 & 0.07 & 0.01 & 0.10 & 0.17 & 0.20 & $\mathbf{0 . 5 9}$ & \\
\hline Brand Loyal & 0.02 & 0.01 & 0.03 & 0.03 & 0.01 & 0.02 & 0.08 & 0.08 & 0.16 & $\mathbf{0 . 5 2}$ \\
\hline
\end{tabular}

model hampir memenuhi kriteria target kecocokan yang baik. Berikut adalah hasil uji Goodness of Fit Structural Model.

Uji Goodness of Fit Measurement Model

\begin{tabular}{|l|l|l|l|}
\hline Ukuran GoF & Target Kecocokan & Hasil Output Model & Keterangan \\
\hline GFI & \multicolumn{1}{|c|}{$>0,9$} & 0,92 & Good Fit \\
\hline AGFI & $>0,9$ & 0,90 & Marginal Fit \\
\hline CMIN/DF & $<3$ & 2,23 & Good Fit \\
\hline RMSEA & $<0,08$ & 0,05 & Good Fit \\
\hline NFI & $\geq 0,90$ & 0,90 & Good Fit \\
\hline CFI & $>0,9$ & 0,94 & Good Fit \\
\hline TLI & $\geq 0,90$ & 0,93 & Good Fit \\
\hline
\end{tabular}




\begin{tabular}{|c|c|c|c|c|}
\hline & Relationships & & Estimate & P-Value \\
\hline H1 & Brand Awareness $\longrightarrow$ & Brand Reputation & 0.280 & $* * *$ \\
\hline $\mathrm{H} 2$ & Service Quality $\longleftrightarrow$ & Brand Reputation & 0.259 & 0.002 \\
\hline H3 & Staff Behavior $\longleftrightarrow$ & Brand Reputation & 0.101 & 0.111 \\
\hline $\mathrm{H} 4$ & Brand Identificati $\longrightarrow$ & Brand Reputation & 0.015 & 0.664 \\
\hline H5 & Self congruence $\longmapsto$ & Brand Reputation & 0.016 & 0.806 \\
\hline H6 & Brand Associati $\longrightarrow$ & Brand Reputation & 0.223 & $* * *$ \\
\hline $\mathrm{H} 7$ & Brand Reputatio $\longrightarrow$ & Brand Satisfaction & 0.465 & $* * *$ \\
\hline H8 & Brand Satisfacti $\rightarrow$ & Brand Trust & 0.515 & $* * *$ \\
\hline H9 & Brand Trust $\longleftrightarrow$ & Brand Loyalty & 0.344 & $* * *$ \\
\hline Var & ce explained $\left(\mathrm{R}^{2}\right)$ & & & \\
\hline $\mathrm{Bra}$ & Reputation & & 0.387 & \\
\hline $\mathrm{Bra}$ & Satisfaction & & 0.208 & \\
\hline $\mathrm{Bra}$ & Trust & & 0.225 & \\
\hline $\mathrm{Bra}$ & Loyalty & & 0.166 & \\
\hline
\end{tabular}

Hasil Output Regression Weight

\section{Kesimpulan}

\subsection{Kesimpulan}

Di antara variabel brand awareness, physical quality, staff behavior, brand identification, self congruence, dan brand association terdapat tiga variabel yang mempengaruhi brand reputation, yaitu brand awareness, physical quality, dan brand association, sedangkan variabel staff behavior, brand identification, dan self congruence tidak mempengaruhi.

5.2 Keterbatasan Penelitian

Penelitian ini memiliki beberapa keterbatasan yang mana keterbatasan tersebut memiliki kemungkinan mempengaruhi hasil penelitian secara keseluruhan. Keterbatasan penelitian ini adalah.

1. Penerjemah indikator atau item pertanyaan pada variabel-variabel yang diteliti memiliki kemungkinan disalah artikan oleh responden.

2. Variabel penelitian yang terbatas seperti brand awareness, service quality, staff behavior, self congruence, brand identification, brand association, brand reputation, brand satisfaction, brand trust. Variabel penelitian diharapkan lebih banyak agar lebih dapat mewakili brand loyalty. 
3. Sampel penelitian yang hanya berjumlah 600 responden. Sampel yang lebih besar diharapkan dapat mewakili populasi.

\section{DAFTAR PUSTAKA}

Aaker, D.A, 1991. Managing Brand Equity. The Free Press, New York.

Aaker, D.A, 2014. Aaker On Branding. The Free Press, New York.

Asaad, P, Lewis, N.K, Palmer, A. / Journal of Business Research 69 (2016) 3033 - 3040.

Barreda, A.A, Bilgihan, A, Nusair, K, Okumus, F. / Tourism Management 57 (2016) 180192.

Bowo,N.H. 2003. Analisis Pengaruh Kepercayaan untuk mencapai hubungan jangka panjang, Jurnal Sains Pemasaran Indonesia. Vol.2.no.1. pp.85-92

Candan, F.B, Ercis, A, Unal, S, Yildirim, H. / Procedia Social and Behavioral Sciences 58 (2012) $1395-1404$.

Chow, H.W, Hwang, K.P, Ling, G.J, Yen, I.Y. / Asia Pacific Management Review xxx (2016) $1-10$.

Cifci, S, Ekinci, Y, Japutra, A, Siala, M, Molinillo, S. / Journal of Business Research 69 (2016) 3740 - 3747.

Ekinci, Y., Dawes, P,L., dan Massey, G.R. (2008) An Extended Model of The Antecedents and Consequences of Consumer Satisfaction for Hospitality Services. European Journal of Marketing, 42(1), 35-68.

Ekinci, Y., Sirakaya-Turk, E., Preciado, S., 2013. Symbolism Consumption of Tourissm Destination Brands. J. Bus. Res. 66(6),711-718.

Foroudi, M.M, Foroudi, P, Gupta, S, Jin, Z, Melewar, T.C. /Journal of Business Research 69 (2016) $4882-4889$.

Han, S.H, Ng.uyen, B.H, dan Lee, T.J. / International Journal of Hospitality Management 50 (2015) $84-93$

Hosany, S., Martin, D., 2012. Self-Image Congruence in Consumer Behavior.J.Bus.Res.65 (5), 685-691.

Keller, K.L. (1993), Conceptualizing, measuring, and managing customer-based brand equity,Journal of Marketing, Vol. 57, January, pp. 1-22.

Keller, K.L (2003), Strategic Brand Management: Building, Measuring and Managing Brand Equity, 2nd Edition. Prentice-Hall, Upper Saddle River, NJ.

Keller, K.L. (2008). Strategic Brand Management: Building Measuring and Managing Brand Equity, 3rd Edition. New Jersey: Pearson Education.

Kotler dan Keller. 2012. Marketing Management Edisi 14. Global Edition.Pearson Prentice Hall.

Kotler dan Keller. 2016. A Framework for Marketing Management Edisi 15. Global Edition.Pearson Prentice Hall.

Lee, D, Kim, Y.J, Moon, J, Yi, M.Y. / Information \& Management 52 (2015) 295 - 304.

Nam, J., Ekinci, Y., Whyatt, G., 2011. Brand Equity, Brand Loyalty and Consumer Satisfaction. Ann. Tourism Res. 38(3), 1009-1030.

Ozsahin, M, Kitapci, H, Sahin, A, Zehir, C. / Procedia Social and Behavioral Sciences 24 (2011) $1218-1231$.

Park, M dan Yoo,J. / Journal of Business Research 69 (2016) 5775 - 5784.

Yeh, C.H, Yieh, K, Wang, Y.S. / International Journal of Information Management 36 (2016) 245 - 257. 
